Janneke Kloosterman

Heidi P. Fransen

Joyce de Stoppelaar

Hans Verhagen

Cathy Rompelberg

\section{Safe addition of vitamins and minerals to foods: setting maximum levels for fortification in the Netherlands}

Received: 20 November 2006

Accepted: 27 March 2007

Published online: 3 May 2007
J. Kloosterman · H.P. Fransen

H. Verhagen · C. Rompelberg ( $\square)$

National Institute for Public Health and the Environment (RIVM)

P.O. Box 1

3720 BA Bilthoven, The Netherlands

Tel.: +31-30/274-2387

Fax: +31-30/274-4466

E-Mail: cathy.rompelberg@rivm.nl

J. de Stoppelaar

Ministry of Public Health, Welfare and Sports

Nutrition, Health Protection and

Prevention Dept.

The Hague, The Netherlands
Abstract Background In 2004, the European Court of Justice decided that the prohibition of fortification with vitamin A, vitamin D, folic acid, selenium, copper, and zinc in the Netherlands conflicts with the principle of free movement of goods in the European Union. This decision led to a change in the Dutch policy, resulting in a more flexible handling of requests for exemption from this prohibition to fortify. Therefore, an investigation was proposed in which it would be determined whether a general exemption could be granted for food fortification with a certain maximum safe amount per micronutrient. Aim of the study To develop a risk assessment model to estimate maximum safe fortification levels (MSFLs) of vitamins and minerals to foods on the Dutch market, and to evaluate these levels to derive allowed fortification levels (AFLs), which can be used for a general exemption. Methods We developed a risk assessment model to estimate MSFLs of vitamins and minerals to foods on the basis of existing models. We used European tolerable upper intake levels in com- bination with national food consumption data to estimate MSFLs for fortification of foods for several age groups. Upon extensive stakeholder dialogue, the risk manager considered these estimated MSFLs and the final AFLs for a general exemption were set. Results For folic acid, vitamin $\mathrm{A}$, and vitamin $\mathrm{D}$, the MSFLs were calculated in the risk-assessment model. Children up to 6-years old were the group most sensitive to folic acid fortification, and they had an MSFL of $0 \mu \mathrm{g} / 100 \mathrm{kcal}$, but following a risk management evaluation, this was upgraded to an AFL of $100 \mu \mathrm{g} / 100 \mathrm{kcal}$. The MSFL for vitamin D was $3.0 \mu \mathrm{g} /$ $100 \mathrm{kcal}$ (children 4-10 years old), and the risk manager increased this to an AFL of $4.5 \mu \mathrm{g} / 100 \mathrm{kcal}$. Children up to 10 years old, men, and postmenopausal women were the groups most sensitive to vitamin A fortification (MSFL $=0 \mu \mathrm{g} /$ $100 \mathrm{kcal}$ ). Because these groups represent a large part of the population and because of the seriously harmful effects of excessive vitamin $A$, the risk manager did not allow a general exemption. Conclusions The combination of a risk assessment model and risk 
manager evaluation led to the setting of AFLs for general exemption of fortification with folic acid and vitamin D. This model is also applicable for other micronutrients, for which an UL is derived, and in other countries.
Key words vitamins minerals - micronutrients fortification - food tolerable upper intake level safe addition - maximum fortification levels

\section{Introduction}

Foods are fortified with micronutrients and other bioactive compounds to prevent deficiencies or to provide additional health effects. Furthermore, the use of health claims on products after fortification is thought to result in better marketing. As fortification with micronutrients should be safe for the whole population, unacceptably large intakes of micronutrients from all sources should be prevented. For this purpose, tolerable upper intake levels (ULs) are established [28].

Because of the small range between recommended daily intakes and ULs and the lack of proof of a nutritional need, fortification with vitamin $A$, vitamin $\mathrm{D}$, folic acid, selenium, copper, and zinc is prohibited in the Netherlands [1]. Addition of these six micronutrients was only allowed in the case of substitution (e.g., vitamins $\mathrm{A}$ and $\mathrm{D}$ in margarine as a substitute for butter) or restoration (for instance, because of losses during processing) [1]. In December 2004, the Court of Justice of the European Communities decided that the prohibition of fortification with these six micronutrients contradicted the free movement of goods, a fundamental principle in the Treaty Establishing the European Community [5]. This decision means that market introduction of fortified foods can only be prohibited if it can be proved that the degree of fortification (e.g., level of fortification or quantity of foods fortified) may harm public health. This decision led to a change of Dutch policy, resulting in a more flexible handling of requests for exemption from the Dutch Commodity Act that prohibits fortification with these six micronutrients [6]. Exemption will only be granted if there is no harm to public health, based on the results of the most recent international scientific research.

Because of this court decision, each request for individual exemption had to be evaluated for the risk of exceeding the UL. At first, requests for individual exemption were evaluated in order of receiving. To evaluate the risk of exceeding the UL, consumption of the new fortified product by the Dutch population was simulated by replacing the unfortified food products with the new fortified product within the Dutch $\mathrm{Na}$ tional Food Consumption Survey (DNFCS) (e.g., the consumption of all kinds of breakfast cereals as monitored within the DNFCS was replaced by the new fortified breakfast cereals). The resulting habitual daily intake (P95) of the micronutrient was compared with the UL. If the UL was not exceeded, the exemption was granted. This approach resulted in the exemption of very few products and turned out to be an unrealistic worst-case approach. Furthermore, the procedure resulted in an administrative overload and long waiting periods for the industry. Therefore, and in anticipation of upcoming European legislation [11], an investigation was proposed in which it would be determined whether a general exemption could be granted for food fortification with a certain maximum safe amount per micronutrient. A model was needed to calculate the national maximum level of a specific micronutrient that can safely be added to foods. Several such models have recently been developed [11-14, 25]. First, an International Life Science Institute (ILSI) Europe model (2002) [14], which was followed by models by Domke et al. [12, 13] and Rasmussen et al. [25]. The latter is an adapted version of the ILSI Europe model [14]. These models were developed for the purpose of calculating the maximum amount of micronutrients that can be added to each $100 \mathrm{kcal}$ of a given food [14, 25] or each food portion [12]. The intake of micronutrients from nonfortified foods and dietary supplements must be taken into account for this calculation. Domke et al. also estimate the maximum amount of micronutrients in dietary supplements by dividing the space between the UL and the level of intake from nonfortified foods. Most models are theoretical approaches, and data regarding their practical use in decision- or policy-making have not yet been published, although the published acceptable levels of addition per $100 \mathrm{kcal}$ by Rasmussen et al. have been implemented as the Danish maximum levels for fortification (Rasmussen, personal communication, 2006). Besides these models that calculate a maximum fortification level, models that calculate the optimal intake for the population (taking into account both too low and too high intakes) are also being developed [15, 26]. In view of the present application, the derivation of maximum safe fortification levels (MSFLs), these models on optimal intake were not taken into account. The question how to create an optimal micronutrient intake is outside the scope of this paper. 
On the basis of the existing models to calculate a maximum fortification level, a model adapted to the Dutch practical situation was developed for the Dutch authorities to derive for the fortification with micronutrients. This article first describes the model for the derivation of maximum amounts of micronutrient fortification in the Netherlands, and then it illustrates the use of the micronutrient specific data and assumptions in the calculation of the MSFLs for folic acid, vitamin $\mathrm{A}$, and vitamin $\mathrm{D}$. The article concludes with the considerations and the final allowed fortification level (AFL) of the risk management.

\section{Methods}

Models to calculate safe maximum levels of addition of micronutrients are published, among others, by ILSI, Rasmussen and Domke [12-14, 25]. We developed a model for the Dutch situation, based on (elements of) the models of ILSI, Rasmussen and Domke. Below, we will amplify on the main differences between the models and our filling-in for the Dutch model.

The ILSI Europe and Rasmussen et al. models differ in several aspects from Domke et al.'s model. Instead of the calculation per portion size as applied by Domke et al., both ILSI Europe and Rasmussen et al. calculate the maximum fortification level per $100 \mathrm{kcal}$. For our Dutch model, we also calculate with $100 \mathrm{kcal}$ portions because the variation in mean daily energy intake is low compared to for instance the variation in micronutrient or carbohydrate intake [29]. Moreover, there is no univocal definition of portion size in the Netherlands. Another important difference is that Domke et al. not only establish maximum fortification levels, but they also establish maximum levels for dietary supplements. Because maximum safe addition levels of vitamins and minerals in dietary supplements will be regulated via European Union legislation, we did not determine them in our model [11]. Similarly to ILSI Europe and Rasmussen et al., we estimated the current intake of micronutrients from dietary supplements and took them into account. Our Dutch model is principally based on the ILSI Europe model [14] and Rasmussen et al.'s extended model [25], with adaptations to the Dutch practical situation. The formula is equal to the one used by Rasmussen et al., however some of the factors are differently derived (see below).

Our model calculates the maximum safe level for fortification with a micronutrient per $100 \mathrm{kcal}$ of the food (MSFL) for various age groups with the mathematical formula presented in Box 1. The lowest MSFL, i.e., the MSFL for the most sensitive group, is then advised to be the overall maximum acceptable forti- fication, as is common practice in toxicological risk assessment.

\section{Tolerable upper intake level (UL)}

The UL is the maximum level of total chronic daily intake of a nutrient that is unlikely to pose a risk of adverse health effects to humans. In general, the UL is related to total daily intake from all sources including nonfortified foods as well as fortified foods and dietary supplements. In Europe, the Scientific Committee on Food (SCF) and the Scientific Panel on Dietetic Products, Nutrition and Allergies (NDA) set agespecific ULs [28]. Due to lack of data, the ULs for children are usually extrapolated from the ULs for adults based on bodyweight. In anticipation of future European policy [11], these age-specific European ULs were used as model input rather than the national ULs, which is similar to the model of Rasmussen et al. [25]. ILSI Europe has also used European ULs, although only the values for men [14].

Box 1. Formula for the calculation of the maximum safe fortification level with micronutrients per 100 kcal food (MSFL) [25].

\begin{tabular}{|c|c|c|c|}
\hline \multicolumn{2}{|r|}{ Risk-assessment } & \multicolumn{2}{|c|}{$\underline{\text { Risk-management }}$} \\
\hline \multicolumn{2}{|c|}{ MSFL $=\left(\mathrm{UL}-\left(\mathrm{Cl}_{95}+\mathrm{SI}\right)\right) /\left(\left(\mathrm{El}_{95} / 100\right)^{*} \mathrm{PFF}_{\mathrm{n}}\right.$} & Evaluation & AFL \\
\hline MSFL & \multicolumn{3}{|c|}{ Maximum safe fortification level per $100 \mathrm{kcal}$} \\
\hline AFL & \multicolumn{3}{|l|}{ Allowed fortification level per $100 \mathrm{kcal}$} \\
\hline UL & \multicolumn{3}{|l|}{ Tolerable upper intake level } \\
\hline $\mathrm{Cl}_{95}$ & \multicolumn{3}{|c|}{$\begin{array}{l}\text { Current intake at the } 95^{\text {th }} \text { percentile of habitual micronutrient intake } \\
\text { distribution of nonfortified foods (background diet), per age group }\end{array}$} \\
\hline SI & \multicolumn{3}{|c|}{ Realistic high intake scenario from dietary supplements } \\
\hline $\mathrm{El}_{95}$ & \multicolumn{3}{|c|}{ Intake at the $95^{\text {th }}$ percentile of habitual energy intake distribution, per age group } \\
\hline $\mathrm{PFF}_{\mathrm{n}}$ & \multicolumn{3}{|c|}{ Proportion of total energy intake that comes from fortified foods } \\
\hline
\end{tabular}

\section{Current intake of energy and micronutrients from nonfortified foods $\left(\mathrm{El}_{95} \& \mathrm{Cl}_{95}\right)$}

Micronutrients are naturally present in the diet (further referred to as 'background diet'). Because it is important to consider the intake from all possible sources to assess the risk, the intake from the background diet has to be included in the calculations. To estimate the intake of energy and micronutrients from the background diet, it is important to use the most up-to-date country- and age-specific data available. In view of the precautionary principle $[3,10]$, we calculated the age-specific habitual intake (also referred to as usual intake) at the 95th percentile of the distribution of energy and the specific micronutrients from the background diet on the basis of data from 
the most recent Dutch National Food Consumption Surveys (DNFCS): DNFCS-3 and DNFCS-2003. The DNFCS-3 was carried out in 1997-1998 for the whole population (1-97 years) and the DNFCS-2003 was carried out in 2003 for young adults (19-30 years) $[16,23]$. In the DNFCS-3, a 2-day dietary record method was used to collect data on two consecutive days. In the DNFCS-2003, data were collected with a 2-day, 24-hour recall method using EPIC-SOFT, a computer-assisted interview method. We estimated the habitual intake of both micronutrients and energy with statistical correction for the within-person variation using the Iowa State University method (C-SIDE software) $[18,20]$.

Rasmussen et al.'s model uses results from the Danish dietary survey in which a 7-day prospective food recall method was used to calculate the daily intake of micronutrients from nonfortified foods (95th percentile) and energy intake (95th percentile) [25]. ILSI Europe used pan-European estimates of the 95th percentile of intake of micronutrients based on seven national surveys. Some of these surveys already include voluntary fortification of foods with micronutrients and the intake of dietary supplements [14]. Furthermore, the pan-European 95th percentile of energy intake was estimated from five national surveys.

\section{Current intake of micronutrients from dietary supplements $(\mathrm{SI})$}

In addition to the intake from the background diet, the micronutrient intake from dietary supplements (SI) has to be taken into account in order to get a good estimate of the total intake from all sources. In the Netherlands, similar to other Western countries, the use of dietary supplements has increased and takes a more important place in the total micronutrient intake [22]. Preferably, the habitual micronutrient intakes of nonfortified foods and dietary supplements are calculated together. This method takes into account the facts that not everybody uses dietary supplements, not all supplement users use the supplements daily, and supplement users and nonusers may have different eating habits [19]. However, due to lack of information about supplement use, a calculation of combined habitual intake is not possible at this time. Therefore, we used two realistic highintake scenarios of dietary supplements based on the limited Dutch dietary supplement data available: one for adults ( $\geq 18$ years old) and one for children (117 years old). The scenario for adults was based on the P90-P95 of both the intake of micronutrients from dietary supplements in young adults (19-30 years) reported by the DNFCS-2003 [22] and the levels of micronutrients present in dietary supplements (for adults) available in the Netherlands [4]. The scenario for children was based on P90-P95 of the infants' intake of dietary supplements [9] and the levels of micronutrients present in dietary supplements for children, that are available in the Netherlands [4].

We determined the SI differently than Rasmussen et al. and ILSI Europe did. Rasmussen et al. chose to set the SI at $100 \%$ of the reference values for the recommended daily intake of vitamins and minerals because this is the content of the most used multivitamin-mineral supplement in Denmark [25]. The ILSI Europe model does not include the intake from dietary supplements because only a minority of the population is expected to use them $[11,14]$.

\section{Fraction of energy intake that can and will be fortified $\left(\mathrm{PFF}_{\mathrm{n}}\right)$}

Not all foods on the market can or will be fortified. The fraction of total energy intake that will finally be fortified consists of two parts: (1) the proportion of total energy intake that can be fortified; for example, it is unlikely that fresh products such as vegetables, fruits and meat will be fortified; and (2) the proportion of the energy intake of foods available for fortification that actually will be fortified. Due to practical constraints such as costs and processing, not all foods available for fortification will be fortified with a particular micronutrient.

The first part of the fraction was set at $30 \%$, which is lower than the $50 \%$ set by both ILSI Europe and Rasmussen et al. Main argument for the lower percentage was that the large part of the energy intake in the Dutch population is delivered by the traditional dinner, which consists in general of fresh products like meat, vegetables, and potatoes. The second part of the fraction was equal to the one ILSI Europe and Rasmussen et al. set at 50\% (worst case). This resulted in a fraction of the energy intake available for fortification $\left(\mathrm{PFF}_{\mathrm{n}}\right)$ of $15 \%$ (i.e., $30 \% * 50 \%$ ).

\section{Results}

\section{Risk assessment: deriving MSFLs}

We illustrate the applicability of the Dutch model by deriving MSFLs of folic acid, vitamin A, and vitamin D. Tables 1, 2, 3 present the factors used for the calculation of the MSFLs for folic acid, vitamin A, and vitamin $\mathrm{D}$. The classification into age groups is based on the age categories used by NDA/SCF to define the ULs [28] and is different for folic acid, vitamin A, and vitamin D. We calculated the 95th percentile of habitual energy intake for each age group. The habitual energy intake of children increases with age 
Table 1 Maximum safe fortification levels and allowed fortification level of folic acid based on Dutch consumption data and European tolerable upper levels of intake for specific age groups

\begin{tabular}{|c|c|c|c|c|c|c|c|c|c|}
\hline \multirow[b]{2}{*}{ Age group } & & \multirow[b]{2}{*}{$n$} & \multirow{2}{*}{$\begin{array}{l}\mathrm{UL} \\
(\mu \mathrm{g} / \text { day })\end{array}$} & \multirow{2}{*}{$\begin{array}{l}\mathrm{Cl}_{95}^{\mathrm{a}} \\
(\mu \mathrm{g} / \text { day })\end{array}$} & \multirow{2}{*}{$\begin{array}{l}\text { SI } \\
(\mu \mathrm{g} / \text { day })\end{array}$} & \multirow{2}{*}{$\begin{array}{l}\mathrm{El}_{95} \text { (SE) } \\
\text { (kcal/day) }\end{array}$} & \multicolumn{2}{|c|}{$\begin{array}{l}\text { Max safe fortification } \\
\text { level (MSFL) }(\mu \mathrm{g} / 100 \mathrm{Kcal})\end{array}$} & \multirow{2}{*}{$\begin{array}{l}\text { Allowed fortification } \\
\text { level (AFL) } \\
\text { ( } \mu \mathrm{g} / 100 \mathrm{kcal})\end{array}$} \\
\hline & & & & & & & $\mathrm{PFF}_{\mathrm{n}}=0.15$ & $\mathrm{PFF}_{\mathrm{n}}=0.10^{\mathrm{b}}$ & \\
\hline Children & $1-3^{c}$ & 254 & 200 & 0 & 300 & 1,890 (67) & 0 & & \\
\hline Children & $4-6^{c}$ & 276 & 300 & 0 & 300 & $1,995(56)$ & 0 & & \\
\hline Children & $7-10^{c}$ & 312 & 400 & 0 & 300 & $2,456(63)$ & 27 & & \\
\hline Children & $11-14^{c}$ & 336 & 600 & 0 & 300 & 3,154 (117) & 63 & & \\
\hline Adolescents & $15-17^{c}$ & 280 & 800 & 0 & 300 & $3,518(150)$ & 95 & & \\
\hline Men & $18-30^{c}$ & 525 & 1,000 & 0 & 600 & $4,010(112)$ & 67 & 100 & 100 \\
\hline Women & $18-30^{c}$ & 579 & 1,000 & 0 & 600 & $2,867(62)$ & 93 & 140 & \\
\hline Men & $19-30^{d}$ & 352 & 1,000 & 0 & 600 & 3,751 (130) & 71 & 106 & 100 \\
\hline Women & $19-30^{\mathrm{d}}$ & 398 & 1,000 & 0 & 600 & $2,581(76)$ & 103 & 155 & \\
\hline Men & $31-50^{c}$ & 950 & 1,000 & 0 & 600 & 3,529 (64) & 76 & 113 & \\
\hline Women & $31-50^{c}$ & 1,100 & 1,000 & 0 & 600 & $2,721(48)$ & 98 & 147 & \\
\hline Men & $51-65^{c}$ & 420 & 1,000 & 0 & 600 & 3,427 (109) & 78 & 117 & \\
\hline Women & $51-65^{c}$ & 479 & 1,000 & 0 & 600 & 2,647 (74) & 101 & 151 & \\
\hline Men & $>65^{c}$ & 260 & 1,000 & 0 & 600 & 3,106 (119) & 86 & 129 & \\
\hline Women & $>65^{c}$ & 410 & 1,000 & 0 & 600 & $2,432(65)$ & 110 & 164 & \\
\hline
\end{tabular}

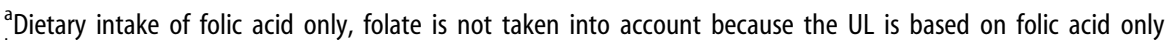

${ }^{\mathrm{b}}$ Additional calculation with exactly the same results as for $\mathrm{PFF}_{\mathrm{n}}=0.15$ in combination with a scenario of low dietary supplement intake (i.e., $400 \mu \mathrm{g}$ ), only calculated for adults

'Based on consumption data from the DNFCS-3 (1997-1998) [2]

Based on consumption data from the DNFCS $2003[17,21]$

The most sensitive age groups are bolded; $\mathrm{Cl}_{95}$, 95th percentile of habitual dietary folic acid intake; $\mathrm{El}_{95}$, 95th percentile of habitual energy intake; $\mathrm{Sl}$, supplement intake; $\mathrm{PFF}_{\mathrm{n}}$, proportion of energy intake that can and will be fortified; UL, tolerable upper intake level

Table 2 Maximum safe fortification levels of vitamin $A^{a}$ based on Dutch consumption data and the European upper levels of intake for specific age groups

\begin{tabular}{|c|c|c|c|c|c|c|c|}
\hline Age group & & $N$ & $\begin{array}{l}\text { UL } \\
(\mu \mathrm{g} / \text { day })\end{array}$ & $\begin{array}{l}\mathrm{Cl}_{95} \text { (SE) } \\
(\mu \mathrm{g} / \text { day })\end{array}$ & $\begin{array}{l}\text { SI } \\
(\mu \mathrm{g} / \text { day })\end{array}$ & $\begin{array}{l}\mathrm{El}_{95} \text { (SE) } \\
\text { (kcal/day) }\end{array}$ & $\begin{array}{l}\text { Max safe fortification } \\
\text { level }(\mathrm{MSFL})(\mu \mathrm{g} / 100 \mathrm{kcal}) \\
\operatorname{PFF}_{\mathrm{n}}{ }^{\mathrm{b}}=0.15\end{array}$ \\
\hline Children & $1-3^{c}$ & 254 & 800 & $1,057(167)$ & 800 & 1890 (67) & 0 \\
\hline Children & $4-6^{c}$ & 276 & 1,100 & $1,553(262)$ & 800 & $1995(56)$ & 0 \\
\hline Children & $7-10^{c}$ & 312 & 1,500 & $1,055(116)$ & 800 & $2456(63)$ & 0 \\
\hline Children & $11-14^{c}$ & 336 & 2,000 & 1,153 (131) & 800 & 3154 (117) & 10 \\
\hline Adolescents & $15-17^{c}$ & 280 & 2,600 & 1,429 (205) & 800 & $3518(150)$ & 70 \\
\hline Men & $19-30^{b}$ & 352 & 3,000 & 1,886 (261) & 1,200 & 3751 (130) & 0 \\
\hline Women & $19-30^{\mathrm{b}}$ & 398 & 3,000 & 1,203 (162) & 1,200 & $2581(76)$ & 154 \\
\hline Men & $\geq 18^{c}$ & 2,155 & 3,000 & 2,363 (132) & 1,200 & $3642(50)$ & 0 \\
\hline Women & $18-50^{c}$ & 1,679 & 3,000 & $1,350(83)$ & 1,200 & 2785 (39) & 108 \\
\hline Women & $>50^{c}$ & 889 & 1,500 & 1,441 (108) & 1,200 & 2555 & 0 \\
\hline
\end{tabular}

a Not including provitamin A

based on consumption data the DNFCS 2003 [17, 21]

'Based on consumption data from the DNFCS-3 (1997-1998) [2]

The most sensitive age groups are bolded; $\mathrm{Cl}_{95}, 95$ th percentile of habitual dietary vitamin A intake; $\mathrm{El}_{95}$, 95th percentile of habitual energy intake; $\mathrm{Sl}$, supplement intake; $\mathrm{SE}$, standard error; $\mathrm{PFF}_{\mathrm{n}}$, proportion of energy intake that can and will be fortified; UL, tolerable upper intake level

(Tables 1-3). The 95th percentile of the habitual energy intake for men is greater than that for women; there is a small decline of habitual energy intake with age for both genders.

\section{Folic acid}

Folic acid is the synthetic form of folate, a natural component in the diet. An UL has been established only for folic acid and not for folate. For this reason, the calculation does not consider the intake of folate from the background diet. At the time the food consumption surveys were conducted, fortification with folic acid was not permitted in the Netherlands, which results in an intake from the background diet $\left(\mathrm{CI}_{95}\right)$ of $0 \mu \mathrm{g} /$ day. The SI of folic acid was estimated to be $300 \mu \mathrm{g} /$ day for children and adolescents and $600 \mu \mathrm{g} /$ day for adults. Filling in these factors in the formula of Box 1 resulted in a maximum fortification level for folic acid of $0 \mu \mathrm{g} / 100 \mathrm{kcal}$ for children 1-6 years old 
Table 3 Maximum fortification levels and allowed fortification level of vitamin D based on Dutch consumption data and European tolerable upper levels of intake for specific age groups

\begin{tabular}{|c|c|c|c|c|c|c|c|c|c|}
\hline \multirow[b]{2}{*}{ Age group } & & \multirow[b]{2}{*}{$n$} & \multirow{2}{*}{$\begin{array}{l}\text { UL } \\
(\mu \mathrm{g} / \text { day })\end{array}$} & \multirow{2}{*}{$\begin{array}{l}\mathrm{Cl}_{95} \text { (SE) } \\
(\mu \mathrm{g} / \mathrm{day})\end{array}$} & \multirow{2}{*}{$\begin{array}{l}\text { SI } \\
(\mu \mathrm{g} / \text { day })\end{array}$} & \multirow{2}{*}{$\begin{array}{l}\mathrm{El}_{95} \text { (SE) } \\
\text { (kcal/day) }\end{array}$} & \multicolumn{2}{|c|}{$\begin{array}{l}\text { Max safe fortification level } \\
\text { (MSFL) }(\mu \mathrm{g} / 100 \mathrm{Kcal})\end{array}$} & \multirow{2}{*}{$\begin{array}{l}\text { Allowed fortification } \\
\text { level (AFL) } \\
(\mu \mathrm{g} / 100 \mathrm{kcal})\end{array}$} \\
\hline & & & & & & & $\mathrm{PFF}_{\mathrm{n}}=0.15$ & $\mathrm{PFF}_{\mathrm{n}}=0.10^{\mathrm{a}}$ & \\
\hline Children & $1-3^{b}$ & 254 & 25 & $4.8(0.6)$ & 10 & $1,890(67)$ & 3.6 & 5.4 & \\
\hline Children & $4-10^{b}$ & 276 & 25 & $4.4(0.2)$ & 10 & $2,334(50)$ & 3.0 & 4.5 & 4.5 \\
\hline Children & $11-13^{b}$ & 312 & 50 & $6.5(0.6)$ & 10 & $2,935(100)$ & 7.6 & 11.4 & \\
\hline Adolescents & $14-18^{b}$ & 336 & 50 & $7.6(0.5)$ & 10 & 3,509 (116) & 6.2 & 9.2 & \\
\hline Men & $19-30^{c}$ & 352 & 50 & $6.5(0.4)$ & 10 & 3,751 (130) & 6.0 & 8.9 & \\
\hline Women & $19-30^{c}$ & 398 & 50 & $5.2(0.4)$ & 10 & $2,581(76)$ & 9.0 & 13.5 & \\
\hline Men & $31-50^{b}$ & 950 & 50 & $8.9(0.4)$ & 10 & $3,529(64)$ & 5.9 & 8.8 & \\
\hline Women & $31-50^{\mathrm{b}}$ & 1,100 & 50 & $6.4(0.3)$ & 10 & $2,721(48)$ & 8.2 & 12.3 & \\
\hline Men & $51-60^{b}$ & 314 & 50 & $11.3(1.2)$ & 10 & 3,410 (128) & 5.6 & 8.4 & \\
\hline Women & $51-60^{\mathrm{b}}$ & 332 & 50 & $6.7(0.6)$ & 10 & $2,623(90)$ & 8.5 & 12.7 & \\
\hline Men & $61-70^{\mathrm{b}}$ & 197 & 50 & $9.8(1.0)$ & 10 & 3,315 (124) & 6.1 & 9.1 & \\
\hline Women & $61-70^{\mathrm{b}}$ & 270 & 50 & $6.6(0.6)$ & 10 & $2,528(87)$ & 8.8 & 13.2 & \\
\hline Men & $>70^{\mathrm{b}}$ & 169 & 50 & $12.2(1.8)$ & 10 & 3,067 (141) & 6.0 & 9.1 & \\
\hline Women & $>70^{\mathrm{b}}$ & 287 & 50 & $8.6(0.8)$ & 10 & 2,487 (86) & 8.4 & 12.6 & \\
\hline
\end{tabular}

${ }^{a}$ Additional calculation with exactly the same results as for $\mathrm{PFF}_{\mathrm{n}}=0.15$ in combination with low scenario of dietary supplement intake (i.e., $5 \mu \mathrm{g}$ )

based on consumption data from the DNFCS-3 (1997-1998) [2]

'Based on consumption data from the DNFCS 2003 [21]

The most sensitive age groups are bolded; $\mathrm{Cl}_{95}, 95$ th percentile of habitual dietary vitamin $\mathrm{D}$ intake; $\mathrm{El}_{95}$, 95th percentile of habitual energy intake; $\mathrm{SI}$, supplement intake; $\mathrm{SE}$, standard error; $\mathrm{PFF}_{\mathrm{n}}$, proportion of energy intake that can and will be fortified; UL, tolerable upper intake level

to $110 \mu \mathrm{g} / 100 \mathrm{kcal}$ for women older than 65 years (Table 1). For children and adolescents, the MSFL for folic acid fortification increased with age because of an increase in UL over the age groups. For adults, men generally had lower MSFLs than women due to a higher energy intake. Based on the most sensitive age group (i.e., children 1-6 years) the MSFL is $0 \mu \mathrm{g} /$ $100 \mathrm{kcal}$. For the most sensitive adult group (i.e., men $18-30$ years old) the MSFL is $67-71 \mu \mathrm{g} / 100 \mathrm{kcal}$. Our calculated MSFL for the most sensitive group is lower for folic acid than the acceptable level of addition of Rasmussen et al., $23 \mu \mathrm{g} / 100 \mathrm{kcal}$ for the most sensitive group (1-3 years old), while we calculated $0 \mu \mathrm{g} /$ $100 \mathrm{kcal}$ for children 1-6 years old. This difference is mainly caused by a lower estimation of the SI by Rasmussen et al., which was based on Danish legislation. In our calculations, the current intakes from dietary supplements were estimated based on the amount of folic acid available in dietary supplements on the Dutch market.

\section{Vitamin A}

Part of the vitamin A is consumed as provitamin A (for instance, carotenoids). However, the UL is defined for the intake of vitamin $A$ as pure retinol and retinyl esters only because it is thought that the intake of provitamin A will not significantly contribute to the toxicity of high intakes of vitamin $A$ [28]. When we use the term 'vitamin A', we refer to pure retinol and retinyl esters. Due to the risk of osteoporosis, the UL for postmenopausal women is much lower than that for other women
[28]. In our study population, the distinction between premenopausal and postmenopausal women could not be made exactly; therefore, it was assumed that women older than 50 years are representative for the group of postmenopausal women.

When the food consumption surveys were carried out, vitamin A addition was only allowed for margarine and low-fat margarine as a substitute for butter. This substitution will continue in the Netherlands, and therefore the fortification of (low-fat) margarine with vitamin A was included in the calculation of the $\mathrm{CI}_{95}$. The SI was estimated to be $800 \mu \mathrm{g}$ vitamin A/day for children and adolescents and $1,200 \mu \mathrm{g}$ vitamin $\mathrm{A} /$ day for adults. The habitual dietary vitamin A intake varied from $1,055 \mu \mathrm{g} /$ day to $2,363 \mu \mathrm{g} /$ day. For children, the age group $4-6$ years had the greatest vitamin A intake (1,553 $\mu \mathrm{g} /$ day). Men had a larger intake than women. The vitamin A intake of premenopausal and postmenopausal women (i.e., older than 50 years) was comparable (Table 2). Filling in these factors in the formula (Box 1) resulted in a MSFL for vitamin $A$ of $0 \mu \mathrm{g}$ vitamin A/100 kcal for children 1-10 years old, men and post-menopausal women, $154 \mu \mathrm{g}$ vitamin $\mathrm{A} / 100 \mathrm{kcal}$ for women 19-30 years old and for older children and adolescents, the MSFL is $10-70 \mu \mathrm{g}$ vitamin $\mathrm{A} /$ day. In conclusion, the MSFL for vitamin A will be $0 \mu \mathrm{g}$ vitamin $\mathrm{A} / 100 \mathrm{kcal}$ on the basis of the most sensitive groups (i.e., children 1-10 years, men 18 years old or more, and postmenopausal women). Our results for vitamin A were the same as Rasmussen et al.'s, i.e., $0 \mu \mathrm{g}$ vitamin A/100 kcal. 


\section{Vitamin D}

At the time when the DNFCS-3 and the DNFCS-2003 were carried out, addition of vitamin $\mathrm{D}$ was only allowed for margarine and low-fat margarine as a substitute for butter. Because this substitution is expected to continue in the Netherlands, this fortification practice was included in the calculation of the $\mathrm{CI}_{95}$. The 95th percentile of habitual dietary vitamin $\mathrm{D}$ intake varied from $4.4 \mu \mathrm{g} /$ day to $12.2 \mu \mathrm{g} /$ day $\left(\mathrm{CI}_{95}\right)$. Vitamin D intake increased with age for children, although children $1-3$ years old had a slightly greater intake than children 4-10 years old. For men, the 95th percentile of habitual vitamin D intake lies between $6.5 \mu \mathrm{g} /$ day and $12.2 \mu \mathrm{g} /$ day and for women, between $5.2 \mu \mathrm{g} /$ day and $8.6 \mu \mathrm{g} /$ day (Table 3). The SI was estimated to be $10 \mu \mathrm{g}$ vitamin $\mathrm{D} /$ day for children, adolescents, and adults.

Entering these factors into the formula (Box 1) resulted in a MSFL for vitamin D of $3.0 \mu \mathrm{g} / 100 \mathrm{kcal}$ for children 4-10 years old to $9.0 \mu \mathrm{g} / 100 \mathrm{kcal}$ for women 19-30 years old. The MSFL increased with age for children, although children 4-10 years old had a slightly lower MSFL than children 1-3 years old. Due to a smaller habitual energy and vitamin D intake, the MSFL for women is greater than that for men. In conclusion, the MSFL of vitamin D is $3.0 \mu \mathrm{g} / 100 \mathrm{kcal}$ based on the most sensitive group (i.e., children 410 years). For the most sensitive adult group (men 51-60 years old), the MSFL is $5.6 \mu \mathrm{g} / 100 \mathrm{kcal}$. Our MSFL for vitamin D $(3.0 \mu \mathrm{g} / 100 \mathrm{kcal}$ for children $4-$ 10 years old) is greater than Rasmussen et al.'s acceptable level of addition: $1 \mu \mathrm{g} / 100 \mathrm{kcal}$ for children 7-10 years old. This is mainly due to the difference in $\mathrm{PFF}_{\mathrm{n}}$. Rasmussen et al. used a more strict $\mathrm{PFF}_{\mathrm{n}}$ of $25 \%$ whereas we used a $\mathrm{PFF}_{\mathrm{n}}$ of $15 \%$.

\section{Risk-management: setting AFLs for general exemption}

After the risk was assessed, a risk manager considered all the important issues and decided what maximum level of fortification will be allowed and included in a general exemption. In the Netherlands, proposed changes and additions to the Dutch Commodity Act are discussed with stakeholders (e.g., organizations of trade and industry, consumers organizations, authorities) in a Regular Consultation on the Commodity Act. Representatives of individual companies cannot participate in the Regular Consultation on the Commodity Act.

Several consultations regarding the results (Tables 1-3) of the risk assessment for fortification with folic acid, vitamin $\mathrm{A}$, and vitamin $\mathrm{D}$ resulted in a general exemption for folic acid of $100 \mu \mathrm{g} / 100 \mathrm{kcal}$ and for vitamin $\mathrm{D}$ of $4.5 \mu \mathrm{g} / 100 \mathrm{kcal}$. No general exemption was given for vitamin A. A main general consideration is that this national policy will be temporary, as European legislation is expected to come into effect within a few years [11].

\section{Folic acid}

The UL of folic acid for adults is based on the risk of masking vitamin $B_{12}$ deficiency, for children an UL is extrapolated from this adult value based on bodyweight. Because of an ongoing discussion about the value of the UL for children extrapolated from the UL for adults, the risk manager decided to focus on the results of the risk assessment for adults only. It was thought that such an extrapolation would be conservative because the risk of vitamin $B_{12}$ deficiency for children was thought to be low. Furthermore, at that time, exemptions had been requested for only a few product types and some specific brands. Therefore, the risk manager expected that the chance of children consuming all available folic-acid-fortified products was small. In discussions with the stakeholders, which considered the temporary character of this national policy and the number of requests for exemption, the $\mathrm{PFF}_{\mathrm{n}}$ of $15 \%$ was judged to be rather conservative. Using the dietary intake at the 95th percentile of the distribution $\left(\mathrm{CI}_{95}\right)$ and the 90-95th percentile of intake from dietary supplements (SI) was also judged to be quite conservative. Therefore, two additional calculations were done, one with a $\mathrm{PFF}_{\mathrm{n}}$ of $10 \%$ and the other with a low intake scenario of dietary supplements (i.e., $400 \mu \mathrm{g}$ for adults). Both scenarios resulted in a maximum level for fortification in the most sensitive adult group (men aged 18-30 years) of 100$106 \mu \mathrm{g} / 100 \mathrm{kcal}$ (Table 1). For practical reasons, the risk manager rounded this value off to an AFL of 100 $\mu \mathrm{g}$ folic acid $/ 100 \mathrm{kcal}$. Because of this relatively liberal AFL and the fact that the value was based on the MLF of adults, it was decided to monitor the intake of folic acid from fortified foods. If the results of the monitoring show that the long-term intake exceeds the UL in specific population groups, appropriate measures can be taken.

\section{Vitamin D}

For vitamin D the derivation of the UL for children is based on critical effects observed in children, whereas for folic acid UL-values for children were established by extrapolation only [28]. Therefore, the maximum fortification levels for children from the risk assessment were considered. As for folic acid, this will be a temporary policy for only a couple of years and it was thought that the $\mathrm{PFF}_{\mathrm{n}}$ of $15 \%$ and the high-intake scenario from dietary supplements are rather conservative estimates. In addition, only one request for 
exemption was received at that time for vitamin D fortification, and the risk manager did not expect more exemption requests. Thus, similar additional calculations with a $\mathrm{PFF}_{\mathrm{n}}$ of $10 \%$ or a scenario of smaller intakes from dietary supplements (i.e., $5 \mu \mathrm{g}$ ) were done for vitamin $\mathrm{D}$. The calculations resulted in a MSFL of $4.5 \mu \mathrm{g}$ vitamin $\mathrm{D} / 100 \mathrm{kcal}$ for the most sensitive group (children aged $4-10$ years) (Table 3 ). The risk manager adopted this MSFL and set the AFL at $4.5 \mu \mathrm{g} / 100 \mathrm{kcal}$. Again, the risk manager desires monitoring of vitamin D and energy intake for insight into current intakes and proportions of energy intake fortified. If long-term intakes exceed the ULs, appropriate measures can be taken.

\section{Vitamin A}

In contrast to the liberalization for folic acid and vitamin $\mathrm{D}$, the risk manager did not liberalize the results from the risk assessments for vitamin A. To the opinion of the risk manager, exceeding the UL of vitamin $\mathrm{A}$ has more serious consequences for public health than exceeding the ULs for folic acid and vitamin $\mathrm{D}$. In addition, the 95th percentile of habitual dietary vitamin A intake of several age groups already exceeded the UL, even without considering the vitamin A intake from dietary supplements. Furthermore, at this time no request for exemption has been received, although one product for which an exemption for folic acid was requested also contained vitamin A. So the AFL was set at $0 \mu \mathrm{g} / 100 \mathrm{kcal}$. The stakeholders in the consultation agreed with this decision.

\section{Exception for low-energy products}

An exception was made for light variants of products (low-energy products). According to the model, products low in energy may be fortified with smaller amounts of the micronutrient than the more energydense counterparts. In view of the obesity trend and the healthy image of light products, this was considered undesirable. Therefore, light products may be fortified with amounts similar to the amounts approved for their more energy-dense counterparts.

\section{Discussion}

We presented a model for the derivation of maximum amounts of micronutrient fortification in the Netherlands. A novelty of this publication is that besides the theoretical model, the practical applicability for the Netherlands is shown including both the riskassessment and risk-management aspects. The model has already contributed to new Dutch policy-making, as the allowed level for fortification for folic acid and vitamin D are applied as a general exemption in 2007 [8].

\section{Applicability of the model}

Although the model can already be applied with the available data in the Netherlands, it is recommended to improve the monitoring of consumption of fortified foods and dietary supplements within the Netherlands. Such data are very useful to check the model parameters and to keep them up-to date. If necessary, AFLs can be adjusted. It is recommended to monitor the intake of fortified foods and dietary supplements as part of the national food consumption survey [7, 27]. Food frequency questionnaires specifically for fortified functional foods and dietary supplements in a representative sample of the population would be a useful tool. In addition composition databases of fortified foods and dietary supplements are recommended [27].

\section{Risk management}

The discussions about the risk-assessment results with the different stakeholders worked well for the risk manager. This resulted in broad insight into the various points of view of the stakeholders. Ultimately the risk manager took the final decision, and in all these cases the stakeholders agreed with the final outcome. The risk assessment was based on the precautionary principle. However, with a view to the fact that this will be a temporary policy, the outcome of the risk assessment was judged to be rather conservative for folic acid and vitamin $D$. In contrast, the market may change, the date the European legislation will come into effect can be later than expected, and people may consume more fortified foods than estimated. Therefore, monitoring the intake of micronutrients from fortified foods is a very important tool for warranting the safety of the population. If monitoring shows that some groups within the population have habitual intakes that exceed the ULs, adaptations should be made. Especially children may be vulnerable. A food consumption survey is currently being conducted among children in the Netherlands. These data will provide insight into the micronutrient intake from natural foods, fortified foods and dietary supplements during 2005/2006.

\section{Additional considerations}

Some factors that were not taken into account in MSFL risk assessment are worth considering, and they can be implemented in the model or taken into 
account in the risk management if necessary. First, we made an exception for the fortification level of 'light' products in our risk management. This exception was not considered in the calculation and can therefore theoretically lead to micronutrient intakes that are too large even if the energy intakes are not exceptionally high. Monitoring the use of fortified 'light' products will be necessary to avoid frequent users exceeding the UL. Second, some products are intended for a specific population or target group only. If there is little risk that the product will be used by nontarget groups, the risk manager can make an exception to the model. Instead of using the calculated MSFL for the most vulnerable group, the MSFL for the specific target group can be used as a maximum for this specific product. Again, monitoring of the use of these products is important, and mentioning the target groups, as well as nontarget groups, on the product package might be considered.

The vitamin levels in products may decrease over time. Therefore, it is possible that the amount of vitamin added by manufacturers is greater than the amount declared on the packages [24]. To be able to protect all consumers and avoid underestimation of the intake, this so-called overage should be integrated into the MSFL in the model. Rasmussen et al. also noted this problem. In Denmark the currently accepted practice is to add up to $150 \%$ of the declared amount. Our calculated MSFL includes overage.

\section{International applicability of the risk-assessment model}

Currently, the European Commission is preparing to set maximum and minimum amounts for vitamins and minerals in both foods and dietary supplements [11]. The simultaneously setting of both the maximum levels for dietary supplements and for foodstuffs can result in a well based division of micronutrients over dietary supplements and fortified foods. Once the choice has been made which micronutrient is allowed to be added to dietary supplements and/or fortified foods, models like the one presented can be helpful to set the MSFL and AFL for micronutrients in food products.

The applicability of the model for this purpose depends on the availability of the input data. When cal- culating MSFLs valid for Europe as a whole, the availability of European data is necessary. However, data from a food consumption survey that cover all Member States of the European Union representatively are not available. Such data are not even available for all Member States individually. Furthermore, consumption data available in various Member States are often collected with different methods, in a different time frame, and for different specific population groups and the fraction of energy intake that can be fortified may differ greatly from country to country because of the various traditional diets. This makes it difficult to estimate the total habitual intake for each micronutrient and energy type at a European level.

To overcome these problems, MSFLs in Europe can be set by using the available country-specific calculations and to select the most sensitive country (i.e., the country with the lowest MSFL). The maximum safe level for fortification for this country can then be applied in all Member States.

\section{Conclusion}

As this paper illustrates, our model for risk assessment can be used in the Netherlands to help risk managers to set maximum levels for safe addition of vitamins to foods. This has resulted in two general exemptions, one for folic acid at $100 \mu \mathrm{g} / 100 \mathrm{kcal}$ and one for vitamin $\mathrm{D}$ at $4.5 \mu \mathrm{g} / 100 \mathrm{kcal}$. The model is flexible and can be adapted to new insights. For example, aspects concerning overage and 'light' products can be included with minor changes in the formula. Monitoring of the total micronutrient intake after applying a general exemption, as well as monitoring of the fortified fraction of the energy intake and the effect of the exception for light products, is recommended for evaluating the model parameters and AFLs and for making adjustments when needed.

\footnotetext{
Acknowledgements We would like to thank Hugo de Sitter (VWA), Martin Kooijman (VWA), Ada Knaap (RIVM), Marja Pronk (RIVM), Bert-Jan Baars (RIVM), Patricia Waijers (RIVM), Marga Ocké (RIVM), Toine Hulshof and other participants of the Regular Consultation on the Commodity Act for the stimulating discussions and valuable comments.
}

\section{References}

1. Anonymous (1996) Warenwetbesluit Toevoeging micro-voedingsstoffen aan levensmiddelen. Staatsblad 311:1-18 [in Dutch]
2. Anonymous (1998) Zo eet Nederland 1998. Resultaten van de Voedselconsumptiepeiling 1998. Voedingscentrum, Den Haag [in Dutch]
3. Anonymous (2000) White paper on food safety. Commission of the European Communities, Brussels 
4. Anonymous (2002) Voeding als medicijn. Alles over vitamines, mineralen en voedingssupplementen. Gezondgids special 32 [in Dutch]

5. Anonymous (2005) Judgment of the Court of 2 December 2004 in case C-41/ 02. Official J Euro Union C19:1

6. Anonymous (2005) Toevoeging microvoedingsstoffen aan levensmiddelen. Staatscourant 48:19 [in Dutch]

7. Anonymous (2006) A model for establishing upper levels of intake for nutrients and related substances. Report of a joint FAO/WHO technical workshop on nutrient risk assessment WHO headquarters, Geneva, Switzerland 2-6 May 2005. WHO/FAO

8. Anonymous (2007) Warenwetregeling vrijstelling toevoeging foliumzuur en vitamine $\mathrm{D}$ aan levensmiddelen. Staatscourant 12:11-12 [in Dutch]

9. Breedveld BC, Hulshof KFAM (2002) Zo eten jonge peuters in Nederland. Resultaten van het Voedingsstoffen Inneming Onderzoek 2002. Voedingscentrum \& TNO, DenHaag \& Zeist [in Dutch]

10. Coppens P, da Silva M, Pettman S (2006) European regulations on nutraceuticals, dietary supplements and functional foods: a framework based on safety. Toxicology 221:59-74

11. Directorate E-Safety of the food chain (2006) Discussion paper on the setting of maximum and minimum amounts for vitamins and minerals in foodstuffs. European Communities

12. Domke A, Grossklaus R, Niemann B, Przyrembel H, Richter K, Schmidt E Weissenborn A, Wörner B, Ziegenhagen $\mathrm{R}$ (2004) Verwendung von Vitaminen in Lebensmitteln. BfR Wissenschaft, Berlin [in German]
13. Domke A, Grossklaus R, Niemann B, Przyrembel H, Richter K, Schmidt E, Weissenborn A, Wörner B, Ziegenhagen $R$ (2004) Verwendung von Mineralstoffen

Lebensmitteln-Toxicologische und ernährungsphysiologische Aspekte. BfR Wissenschaft, Berlin [in German]

14. Flynn A, Moreiras O, Stehle P, Fletcher R, Muller D, Rolland V (2003) Vitamins and minerals: a model for safe addition to foods. Eur J Nutr 42:118-130

15. Hirvonen T, Sinkko H, Valsta LM, Pietinen P. Computional method to discover the optimal food fortification practice. In: Sixth international conference on dietary assessment methods: complementary advances in diet and physical activity assessment methodologies. SY17-04

16. Hulshof KF, Brussaard JH, Kruizinga AG, Telman J, Lowik MR (2003) Socioeconomic status, dietary intake and 10 y trends: the Dutch National Food Consumption Survey. Eur J Clin Nutr 57:128-37

17. Hulshof KFAM, Ocké MC, van Rossum CTM, Buurma-Rethans EJM, Brants HAM, Drijvers JJMM, Ter Doest D (2004) Resultaten van de Voedselconsumptiepeiling 2003. RIVM/ TNO, Bilthoven [in Dutch]

18. Nusser SM, Carriguiry AL, Dodd KW, Fuller WA, Jensen HH (1996) A User's Guide to C-SIDE (Software for Intake Distribution Estimation). Version 1.0. Dietary Assessment Research Series Report 8 (Technical Report g6-TR 31). Center for Agricultural and Rural Development, Iowa State University, Ames (available at: www.card.iastate.edu)

19. Jong $\mathrm{N}$ de, Ocke MC, Branderhorst HA, Friele R (2003) Demographic and lifestyle characteristics of functional food consumers and dietary supplement users. Br J Nutr 89:273-81
20. Nusser S, Carriquiry A, Dodd K, Fuller W (1996) A semiparametric transformation approach to estimating usual daily intake distributions. J Am Stat Assoc 91:1440-1449

21. Ocké MC, Hulshof KFAM, BuurmaRethans EJM, van Rossum CTM, Drijvers JJMM, Brants HAM, Jansen-van der Vliet M, Laan JD van der (2004) Voedselconsumptiepeiling 2003. Samenvatting werkwijze en evaluatie. RIVM, Bilhoven [in Dutch]

22. Ocké MC, Buurma-Rethans EJM, Fransen HP (2005) Dietary supplement use in the Netherlands. Current data and recommendations for future assessment. RIVM, Bilthoven

23. Ocké MC, Hulshof KFAM, Rossum CTM van (2005) The Dutch national food consumption survey 2003. Methodological issues. Arch Public Health 63:227-241

24. Quinlivan E, Gregory J3 (2003) Effect of food fortification on folic acid intake in the United States. Am J Clin Nutr 77:221-225

25. Rasmussen S, Andersen N, Dragsted L, Larsen J (2005) A safe strategy for addition of vitamins and minerals to foods. Eur J Nutr 45:123-135

26. Renwick A, Flynn A, Fletcher R, Muller D, Tuijtelaars S, Verhagen H (2004) Risk-benefit analysis of micronutrients. Food Chem Toxicol 42:1903-22

27. Rompelberg CJM, Jager M, Bakker MI, Buurma-Rethans EJM, Ocké MC (2006) Functional food monitoring as part of the new Dutch dietary monitoring system. RIVM, Bilthoven

28. Scientific Committee on Food and Scientific Panel on Dietetic Products Nutrition and Allergies (2006) Tolerable upper intake levels for vitamins and minerals. European Food Safety Authority

29. Van Staveren WA, Ocké MC (2001) Estimation of dietary intake. In: Bowman BA, Russell RM (eds) Present knowledge in nutrition, 8th edn. ILSI Press, Washington, DC 